\title{
Porous and Lamellar Molybdenum Oxide MonoCrystalline with Hexagonal Structure
}

\author{
F. Paraguay-Delgado ${ }^{1}$, O. Solis-Canto ${ }^{1}$, C. Ornelas ${ }^{1,2}$ and J. Lara-Romero ${ }^{2}$ \\ 1. Centro de Investigación en Materiales Avanzados SC (CIMAV), Laboratorio Nacional de Nanotecnología, \\ Chih., México. \\ 2. Facultad de Ingeniería Química, Universidad Michoacana de San Nicolás de Hidalgo, Mich., Mexico.
}

Molybdenum is an important transition metal, both in oxide $\left(\mathrm{MoO}_{\mathrm{x}}\right)$ and sulfurized $\left(\mathrm{MoS}_{2}\right)$ form are widely used in different applications like gas sensors, photochromic materials, recording materials, catalyst, ceramics, lubricants, etc [1]. Molybdenum sulfide $\left(\mathrm{MoS}_{2}\right)$ is usually synthesized from $\mathrm{MoO}_{\mathrm{x}}$ by means of sulfidation process; always the morphology, shape and size of $\mathrm{MoO}_{\mathrm{x}}$ have strong influence in the final properties and applications of sulfurized molybdenum materials. Different $\mathrm{MoO}_{\mathrm{x}}$ morphologists and crystalline structures are synthesized in precise controlled way and thermic treatments are used to achieve phase transformation and/or crystals grow of the material [3].

In this research work Molybdenum oxide $\left(\mathrm{MoO}_{3}\right)$ was synthesized by microwave assisted hydrothermal method according to previously method reported by Paraguay-Delgado et al [3]. In order to obtain a more stable molybdenum oxide phase, a thermal treatment was performed. The Molybdenum oxide was synthesized from an aqueous solution of ammonium heptamolybdate $\left(\left(\mathrm{NH}_{4}\right)_{6} \mathrm{Mo}_{7} \mathrm{O}_{24} \cdot 4 \mathrm{H}_{2} \mathrm{O}\right)$ at concentration of $0.3 \mathrm{M}$ and $\mathrm{pH}$ controlled, this solution was heated in microwave assisted hydrothermal method at $200^{\circ} \mathrm{C}$ and 41 bar for 20 minutes. Later the $\mathrm{MoO}_{3}$ samples were heated in a muffle at $450^{\circ} \mathrm{C}$ for $45 \mathrm{~min}$ in static atmosphere. After thermal treatment the materials were characterized by XRD, SEM and HRTEM.

By means of XRD the formation of Orthorhombic $\mathrm{MoO}_{3}$ phase was confirmed. SEM characterization was perform in order to know the morphology and composition, the micrographs confirm $\mathrm{MoO}_{3}$ and a hexagonal type bars morphology with average of $11.9 \mathrm{~nm}$ and $3.8 \mathrm{~nm}$ long and diameter respectively. They are formed by terraces (figure 1 a)); its formation in the hexagonal bars was observed in longitudinal or transverse directions. In addition, a complete HRTEM characterization of hexagonal bars with terraces was done, the figure $1 \mathrm{~b}$ ) shows a $\mathrm{Z}$ contrast image in HRTEM, this micrograph shows a part of the hexagonal bar. The $Z$ Contrast observes two different structures, the firs one is the terraces observed in SEM these are $\mathrm{MoO}_{3}$ layered as lamellar $\mathrm{MoO}_{3}$ with different thickness $(\mathrm{Z1})$, according to with Tao Liang, et al, the Orthorhombic $\mathrm{MoO} 3$ form lamellar structures have van der Waals forces between layers [4]. The second structure observed by $\mathrm{Z}$ contrast is a porous crystalline structure join to the lamellas exposed in the outside part of the structure. Figure 2 shows the select area electron diffraction in both areas, terraces and porous structures, the results show the same crystalline structure and the same crystal orientation, perpendicular to the $(-1,1,1)$ plane, this demonstrates the formation of molybdenum oxide porous-layered mono crystal with hexagonal structures. Another HRTEM analyses are congruent, these structures are due the physical change process in thermal treatment.

\section{References:}

[1] J. Zhou et al, J. Mater. Chem. A. 3 (2015) p7463.

[2] M. A. Albiter et al, Nanotechnology. 17 (2006), p3473. 
[3] M. Santos-Beltran et al, J Mater Sci: Mater Electron 28, I 3 (2017), p.2935.

[4] T. Liang et al, PHYSICAL REVIEW B. 77 (2008), p104105-1 104105-2
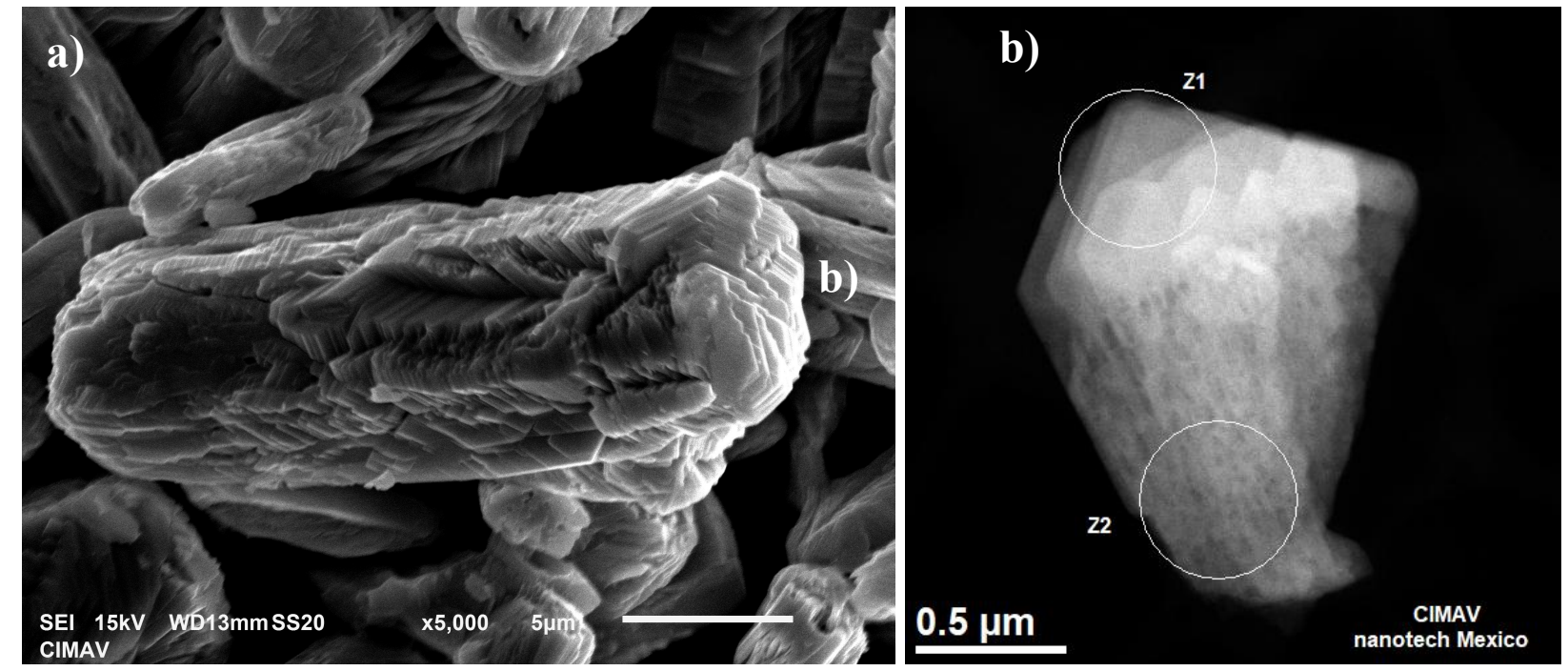

Figure 1. Molybdenum oxide characterization by a) SEM and b) HRTEM (Z-Contrast).

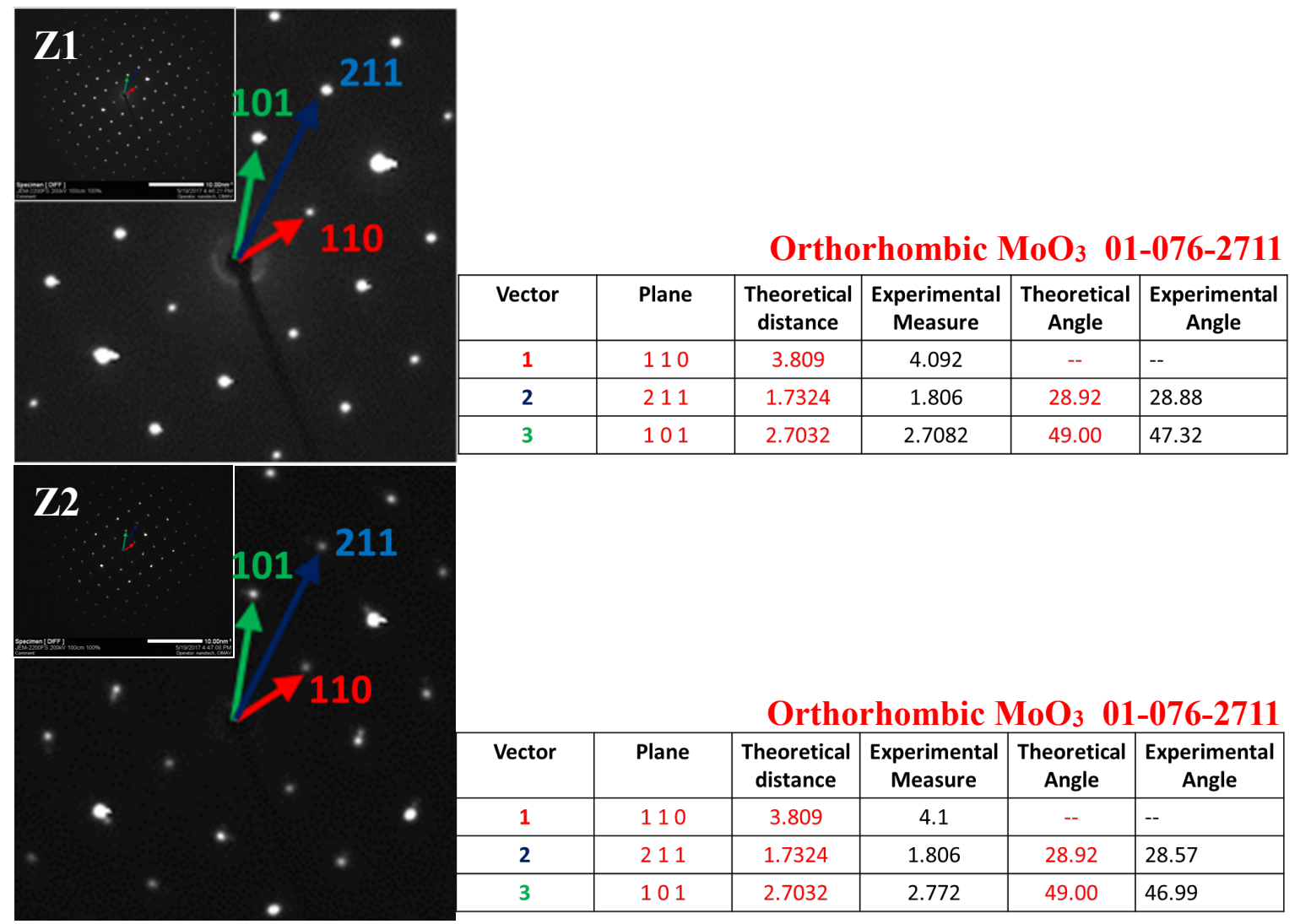

Figure 2. SAD of molybdenum oxide (figure $1 \mathrm{~b}$ )) in $\mathrm{Z} 1$ and $\mathrm{Z} 2$. 